\title{
Drug errors related to self-medication in Morocco
}

\author{
Sara Jadda ${ }^{1,3, *}$, Hinde Hami $^{1}$, Naima Rhalem ${ }^{2}$, Sanou Khô Coulibaly ${ }^{1}$, Abdelrhani Mokhtari ${ }^{3}$, Rachida Soulaymani- \\ Bencheikh $^{2}$, and Abdelmajid Soulaymani ${ }^{3}$ \\ ${ }^{1}$ Faculty of Medicine and Odonto-Stomatology, University of Sciences, Techniques and Technologies, Bamako, Mali \\ ${ }^{3}$ PPR-B-Mokhtari-FS-UIT-Kenitra, Laboratory of Biology and Health, Faculty of Science, Ibn Tofail University, Kenitra, Morocco \\ ${ }^{2}$ Moroccan Poison Control Center, Rabat, Morocco
}

\begin{abstract}
Introduction: Self-medication refers to the act of obtaining a drug without a prescription in order to use it for treatment. The objective of this study is to describe the epidemiological characteristics of drug errors related to self-medication in Morocco. Method: This is a retrospective study of drug errors related to self-medication, reported to the Moroccan Poison Control Center between 2014 and 2018. Results: During the study period, 99 medication errors were recorded, of which $31.6 \%$ concerned children under the age of 15 years. The average age of the patients was 26.6 years. The sex ratio was balanced, with 4 breastfeeding women. Almost all of cases (94.9\%) occurred at home. Drugs acting on the nervous system accounted for $39.4 \%$ of notifications. This was a medicine error in $47.5 \%$ of cases. The patient himself was responsible for the error in $57.6 \%$ of cases. Drug administration was oral in $84.5 \%$ of cases. Of all error cases, $32.7 \%$ were symptomatic. Conclusion: The dangers of self-medication are multiple. Sometimes, self-medication can lead to severe complications. It therefore strongly recommended to follow the medical prescription and the pharmacist's instructions as well as to educate the public about the risks associated with self-medication.
\end{abstract}

Keywords: Medication errors; Self-medication; Morocco

\section{Introduction}

Medication errors are a major public health problem worldwide [1]. They cause significant mortality and morbidity [2,3]. This risk continues to worsen given the lack of awareness, training and information of health professionals and the global population on the damage that can be caused by drug misuse, and due to the lack of studies carried out in this direction. Medication errors can be related to any stage of the drug circuit, as well as they can occur following self-medication which relates to the selection and use of medicines by individuals (or a family member) to treat self-recognized or selfdiagnosed illnesses or symptoms. Several benefits have been linked to appropriate self-medication, among them: access to essential medicines for the patient, active role of the patient in his/ her health care, better use of physician and pharmacist skills, reduction in healthcare costs linked to the treatment of minor health problems $[4,5]$. However, self-medication is far from being a completely safe practice, in particular in the case of nonresponsible self-medication. Potential risks of selfmedication practices include medication errors [6]. Self-medication is an element of self-care that has traditionally been defined as « the taking of drugs, herbs or home remedies on one's own initiative, or on the advice of another person, without consulting a doctor » [7]. Self-medication is a universal phenomenon which is widely practiced in developing countries as many drugs are prescribed over the counter without the guidance of physician [8]. Previous studies reported that selfmedication is commonly practiced in the world and the patients who medicate themselves were in higher incidence of false diagnosis and treatment complications as compared to patients who were consulted by the physician [9].

Self-medication, when practiced appropriately may relieve mild pain [10]. However, if it is adopted inappropriately, it may be harmful or increases the risk of medication errors [11]. Developing drug resistance, drug toxicity, loss of the drug effectiveness, drug abuse and prolong the morbidity are serious potential risks that are associated with the continuous use of over-thecounter (OTC) drugs [12-14]. 
At the national level, very little research had been done in this sense. Therefore, the present study aims to describe the epidemiological profile of medication errors related to self-medication practice in Morocco.

\section{Methods}

This is a retrospective study of medication errors related to self-medication practice, received by the telephone response unit at the Moroccan Poison Control Center over a 5-year period from 2014 to 2018.

The statistical methodology was based on two axes: descriptive statistics and analytical statistics. Descriptive analysis is done using IBM SPSS Statistics (v21) software. It concerns the characteristics linked to the patient (gender, age, origin, place of poisoning), the characteristics of the drug in question (therapeutic class, route of administration), as well as the characteristics linked to the error (type of medication error and responsible for medication error, signs and symptoms, hospitalization, outcome), which allowed us to draw up the epidemiological profile of all notified cases. The age distribution of cases is given according to international standards (WHO) Newborn [0-4 weeks[, Infant [4 weeks-1 year[, Toddler [1-5 years[, Child [5-15 years[, Teenager [15-20 years[, Adult [20-65 years[, Elderly $\geq$ 65 years. The chi-square test allowed us to study the associations between the studied variables and the outcome.

\section{Results}

During the study period, 99 medication errors related to self-medication practice were reported to the Moroccan Poison Control Center. The frequency of notifications increased significantly in 2018 to reach a percentage of $34.3 \%$ (34 cases) (Figure 1).

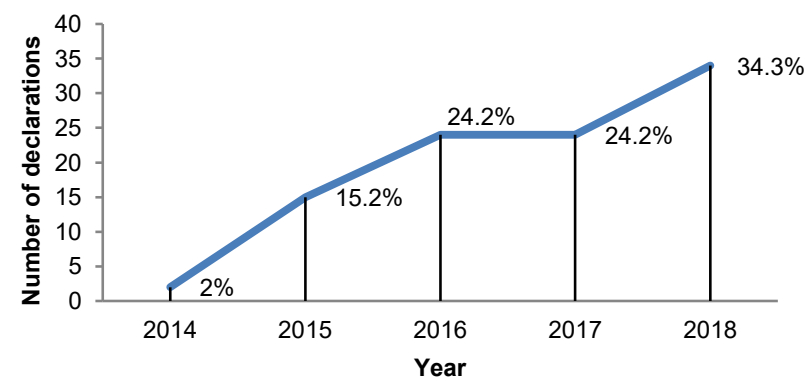

Fig. 1. Time evolution of the medication errors frequency

The average age of the patients was 26.6 years. The toddler group was concerned by $19.2 \%$ of errors (Figure 2).

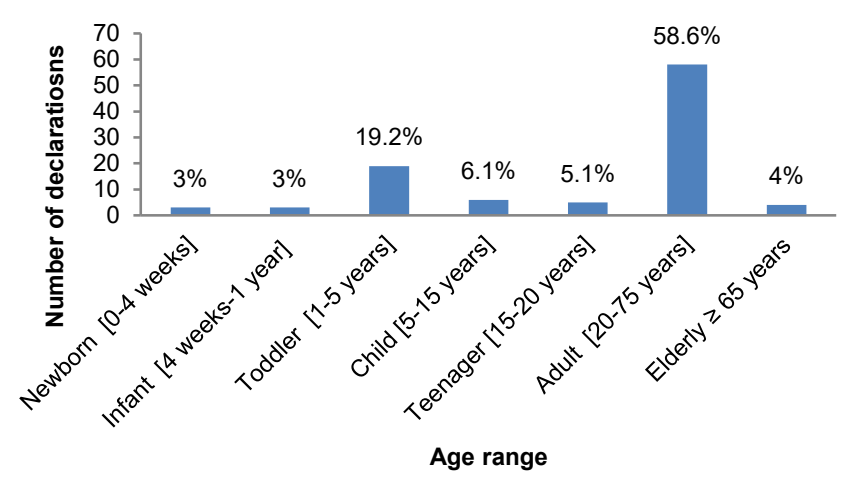

Fig. 2. Age distribution of reported medication errors cases

The male and female sex represents equal number of cases, with 4 breastfeeding women. Thus, $73.7 \%$ of the reports were from urban origin. The therapeutic classes involved in the study were varied and acted on different systems of the human body. According to the results, drugs acting on the nervous system were the most represented with a percentage of $39.4 \%$ (Table 1 ).

Table 1. Distribution of drugs involved in medication errors

\begin{tabular}{|l|r|r|}
\hline \multicolumn{1}{|c|}{ Drug classification } & $\begin{array}{c}\text { Number } \\
\text { of cases }\end{array}$ & $\begin{array}{c}\text { Prevalence } \\
\text { (\%) }\end{array}$ \\
\hline Anti-infective drugs & 8 & 8.1 \\
\hline Antiparasitic drugs & 2 & 2.0 \\
\hline Dermatological drugs & 1 & 1.0 \\
\hline $\begin{array}{l}\text { Drugs for genito-urinary } \\
\text { system and sex hormones }\end{array}$ & 5 & 5.1 \\
\hline Hematologic drugs & 6 & 6.1 \\
\hline $\begin{array}{l}\text { Drugs for cardiovascular } \\
\text { system }\end{array}$ & 5 & 5.1 \\
\hline $\begin{array}{l}\text { Musculo-skeletal system } \\
\text { drugs }\end{array}$ & 5 & 5.1 \\
\hline Nervous system drugs & 39 & 39.4 \\
\hline Respiratory system drugs & 7 & 7.1 \\
\hline $\begin{array}{l}\text { Alimentary tract and } \\
\text { metabolism drugs }\end{array}$ & 19 & 19.2 \\
\hline Unknown & 2 & 2.0 \\
\hline Total & $\mathbf{9 9}$ & $\mathbf{1 0 0 . 0}$ \\
\hline
\end{tabular}

According to the study, the drug error was the type of $47.5 \%$ of the reported cases. The patient himself was responsible for the error in $57,6 \%$ of the cases. Home poisoning was the most recorded in $94.9 \%$ of errors. Drug administration was oral in $84.5 \%$ of cases.

Of the reported errors, $32.7 \%$ were symptomatic with 7 cases requiring hospitalization or prolongation of hospitalization. Among 85 errors for whom the outcome was known, 2 female patients, aged 18 and 27 years, represented sequelae due to patient and drug errors, respectively (Table 2 ). 
Table 2. Characteristics of medication errors

\section{Discussion}

\begin{tabular}{|c|c|c|c|c|c|c|c|}
\hline Characteristics & & $\begin{array}{l}\text { Number } \\
\text { of cases }\end{array}$ & $\begin{array}{c}\text { Prevalence } \\
\text { (\%) }\end{array}$ & Sequelae & $\begin{array}{c}\text { Outcome } \\
\text { Favorable }\end{array}$ & Unknown & p-value \\
\hline \multirow{6}{*}{ Gender } & Female & 48 & 48.5 & 2 & 42 & 4 & \multirow{3}{*}{0.33} \\
\hline & Male & 47 & 47.5 & - & 38 & 9 & \\
\hline & Unknown & 4 & 4 & - & 3 & 1 & \\
\hline & Total & 99 & 100 & 2 & 83 & 14 & \multirow{9}{*}{0.07} \\
\hline & Newborn & 3 & 3.1 & - & 1 & 2 & \\
\hline & Infant & 3 & 3.1 & - & 3 & - & \\
\hline \multirow[t]{8}{*}{ Age group } & Toddler & 19 & 19.2 & - & 16 & 3 & \\
\hline & Child & 6 & 6.1 & - & 6 & - & \\
\hline & Teenager & 5 & 5.1 & 1 & 4 & - & \\
\hline & Adult & 58 & 58.6 & 1 & 50 & 7 & \\
\hline & Elderly & 4 & 4 & - & 2 & 2 & \\
\hline & Unknown & 1 & 1 & - & 1 & - & \\
\hline & Total & 99 & 100 & 2 & 83 & 14 & \multirow{7}{*}{0.79} \\
\hline & Rural & 4 & 4 & - & 3 & 1 & \\
\hline \multirow[t]{6}{*}{ Origin } & Urban & 73 & 73.7 & 2 & 60 & 11 & \\
\hline & Unknown & 22 & 22.2 & - & 20 & 2 & \\
\hline & Total & 99 & 100 & 2 & 83 & 14 & \\
\hline & Dose & 16 & 16.2 & - & 14 & 2 & \\
\hline & Drug & 47 & 1 & 1 & 40 & 6 & \\
\hline & Expired drug & 14 & 11.1 & - & 13 & 1 & \multirow[t]{4}{*}{$<0.05^{* *}$} \\
\hline \multirow[t]{4}{*}{ Type of $\mathrm{ME}^{*}$} & Patient & 2 & 2 & 1 & 1 & - & \\
\hline & Posology & 18 & 10.1 & - & 13 & 5 & \\
\hline & Monitoring & 2 & 2 & - & 2 & - & \\
\hline & Total & 99 & 100 & 2 & 83 & 14 & \multirow{4}{*}{0.80} \\
\hline \multirow{4}{*}{$\begin{array}{l}\text { Responsible of } \\
\mathrm{ME}^{*}\end{array}$} & Patient himself & 57 & 57.6 & 1 & 49 & 7 & \\
\hline & Patient's entourage & 42 & 42.4 & 1 & 34 & 7 & \\
\hline & Total & 99 & 100 & 2 & 83 & 14 & \\
\hline & Symptomatic & 32 & 32.7 & 2 & 26 & 4 & \multirow{3}{*}{0.34} \\
\hline \multirow[t]{2}{*}{ Symptomatology } & Asymptomatic & 66 & 66.3 & - & 56 & 10 & \\
\hline & Unknown & 1 & 1 & - & 1 & - & \\
\hline \multirow{5}{*}{ Hospitalization } & Total & 99 & 100 & 2 & 83 & 14 & \multirow{5}{*}{0.26} \\
\hline & Yes & 7 & 7.1 & - & 7 & - & \\
\hline & No & 32 & 32.3 & 1 & 28 & 3 & \\
\hline & Unknown & 10 & 10.1 & 1 & 48 & 11 & \\
\hline & Total & 99 & 100 & 2 & 83 & 14 & \\
\hline
\end{tabular}

Clinically, the patients presented various signs (Figure 3 ). Among the 32 cases with symptoms, 11 patients presented hepato-digestive disorders.

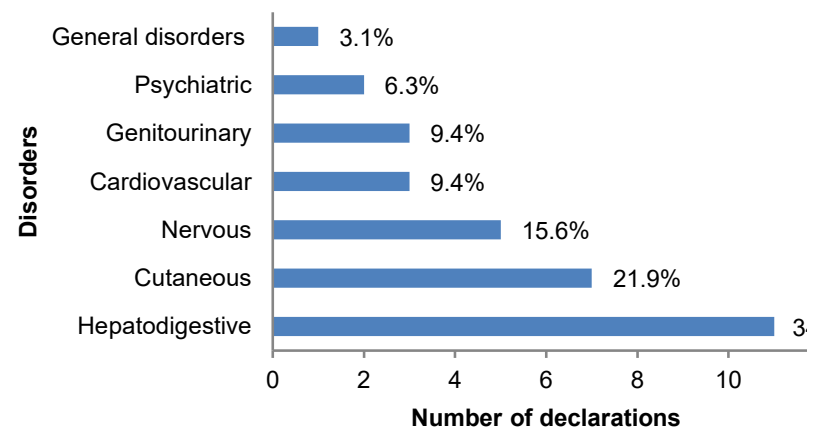

Fig. 3. Distribution of cases by system organ class affected
The frequency of occurrence of medication errors differs from one patient to another. They are even more serious than the therapeutic margin of the drug is narrow and turn out to be more severe in sensitive age range such as children or elderly [15]. Patients receiving aggressive treatment are also at high risk and require increased vigilance, as do children and women, especially pregnant or breastfeeding women [16].

According to the figure 1, the results of the present study shown that the medication error reporting in Morocco has increased since the establishment of the medication error management unit. Medication errors have been analyzed as a health professionals responsibility (due to mistakes in prescription, preparation, dispensing,...). However, sometimes, patients themselves (or their caregivers) make mistakes in the administration of the drug [17].

The epidemiology of drug errors related to selfmedication has been scarcely reviewed in spite of its impact on people, on therapeutic effectiveness and on incremental health care costs $[17,18]$. In our study, the patient himself was responsible for the error in $57.6 \%$ of the cases, while the patient's entourage was implicated in $42.4 \%$ of the errors. According to a study conducted in Amman, the capital city of Jordan, it is found that the patient's entourage and pharmacists were the most 
common sources of self-medication errors [19]. These important data show that self-medication is a real problem that can affect public health following the occurrence of medication errors.

Different studies have investigated the types behind selfmedication errors. The most commonly reported was dosing error, followed by missed dose, wrong drug and incorrect route of administration [20]. In our study, dose error $(16.2 \%)$, expired drug $(11.1 \%)$, and posology error $(10.1 \%)$ were the most frequently observed. Many studies reported that the most commonly used drugs as self-medication were analgesics, antibiotics and vitamins [21]. According to our results, $39.4 \%$ of errors were related to drugs acting on the nervous system.

Other several studies also described factors which contributed to the occurrence of self-medication errors. The most commonly reported factor was complex treatment regimens due to use of multiple medicines [22]. Other factors identified included cognitive decline, lack of social support, lack of knowledge about treatment regimens, negative attitudes and beliefs towards medicines. In most cases, the errors occurred when multiple contributing factors were present [23]. Another study in Saudi Arabia reported that the selfmedication errors can be mainly reduced by improving doctor's handwriting and reducing the load of working [24]. Misreading the prescription and confusing similar names or packaging were the main causes of selfmedication errors in the United Kingdom [25]. A previous study in Nigeria reported that the reasons behind the prevalent use of OTC medications were the following: desire to save money, presence of mild health, previous experience with drug efficacy and long waiting times in public hospitals [26].

The literature highlights a number of types of selfmedication errors and their contributing factors which occur in the large population. Given that many errors are preventable, more research is needed into the factors contributing to self-medication errors [27]. Nowadays, health professionals and the general population are urged to provide a wide variety of activities that are essential in the health care system. Several studies have shown that the pharmacist interventions can help improve patient safety as a source of drug information since they have the potential to make a huge impact in reducing the incidence of the risk associated with selfmedication errors [28].

\section{Conclusion}

The dangers of self-medication are multiple. Sometimes, self-medication can lead to severe complications. It is therefore strongly recommended to follow the medical prescription and the pharmacist's instructions as well as to educate the public about the risks associated with selfmedication.

\section{References}

1. W. Shaohan, W. Haikuan, Iran. J. Public Health, 47, 1052 (2018)
2. F. Annegret, J. Public Health Res., 1, 214-215 (2012)

3. R. Poole, B. Carleton, J. Pediatr. Pharmacol. Ther., 13, 65-67 (2008)

4. J. Aronson, Int. J. Med., 102, 513-521 (2009)

5. M. AL-Arifi, Saudi Pharm., 22, 195-202 (2014)

6. M. Hernandez, J. Quesada, Med. Oral, 7, 344-347 (2002)

7. O. Y. Alshogran, K. H. Alzoubi, O. H. Khabour, S. H. Farah, Risk Manag. Health Policy, 11, 169-176 (2018)

8. H.G. Bagewadi, P.M. Deodurg, B.V. Patil, S.H. Zahid, Int. J. Basic Clin. Pharmacol., 7, 63-67 (2018).

9. H. Shah, R. Patel, S. Nayak, H. Patel, D. Sharma, Int. J. Med. Sci. Public Health, 7, 249-254 (2018)

10. D.M. Ashcroft, C. Morecroft, D. Parker, P. Noyce, Qual. Saf. Health Care, 14, 417-421 (2005)

11. Y.M. AL-WorafiI, Asian J. Pharm. Clin. Res., 11, 478-481 (2018)

12. A. Beso, B. Franklin, N. Barber, Pharm. World Sci., 27(3), 182-190 (2005)

13. K.C. Cheung, M. Bouvy, P.A. De Smet, Br. J. Clin. Pharmacol., 67, 676-680 (2009)

14. P. Knudsen, H. Herborg, A.R. Mortensen, M. Knudsen, A. Hellebek, Qual. Saf. Health Care, 16, 285-290 (2007)

15. M. Haddad, M. Ebada, J. Public Health Res., 6 (1), 818 (2017)

16. M. Hamel, A. Odhacha, J. Roberts, M. Deming, Bull. World Health Organ., 79, 1014-1023 (2001)

17. R.M. Helal, H.S. Abou-Elwafa, J. Environ. Public Health, 9145193 (2017)

18. K. Aldhwaihi, F. Schifano, C. Pezzolesi, N. Umaru, Integr. Pharm. Res. Pract., 5, 1-10 (2016)

19. M. Isa, A. AL-Atoom, H.S Farah, Int. J. Pharm. Sci. Healthc, 7, 19-34 (2017)

20. H. James, S. Handu, K. Al Khaja, S. Otoom, R. Sequeira, Med. Princ. Pract., 15, 270-275 (2006)

21. G. De Oliveira, L. Castro-Alves, M.C. Kendall, R. McCarthy, J. Patient Saf., 17 (5), 375-380 (2021)

22. J.A. Lukovic, V. Miletic, T. Pekmezovic, G. Trajkovic, N. Ratkovic, D. Aleksic, A. Grgurevic, PLoS One, 9 (12), e114644 (2014)

23. S. Scobie, R. Thomson, Building a memory: preventing harm, reducing risks and improving patient safety (National Patient Safety Agency, London, UK, 2005)

24. J. Pal, S. Ahmad, P. Pal, D. Chatterjee, Int. J. Community Med. Public Health, 4, 3619-3624 (2017)

25. D.M. Ashcroft, P. Quinlan, A. Blenkinsopp, Drug Saf., 14, 327-332 (2005)

26. J. Smith, G. Cavell. Building a safer NHS for patients: improving medication safety (Chief Pharmaceutical Office, UK, 2004)

27. A. Yousef, A. Al-Bakri, Y. Bustanji, M. Wazaify, Pharm. World Sci., 30, 24-30 (2008)

28. E. Gogazeh, Saudi Pharm. J., 28, 233-237 (2020) 